\title{
Effect of Methanol Extract of Cassia occidentalis L. Root on Body Organs of Alloxan Induced Diabetic Rats
}

\author{
${ }^{1}$ R. Garba, ${ }^{1}$ A.N. Saidu, ${ }^{1}$ H.R.Y. Adeyemi, ${ }^{1}$ H.L. Muhammad and ${ }^{2}$ S.K. Abubakar-Akanbi \\ ${ }^{1}$ Department of Biochemistry, Federal University of Technology, Minna, Niger-State, Nigeria \\ ${ }^{2}$ Department of Morbid Anatomy, Federal Medical Centre, Bida, Niger State, Nigeria
}

\begin{tabular}{|c|c|}
\hline $\begin{array}{l}\text { Correspondence } \\
\text { R. Garba, Department of } \\
\text { Biochemistry, Federal University of } \\
\text { Technology, Minna, Niger-State, } \\
\text { Nigeria, Tel.: +2348052166759; } \\
+2347031349036 \\
\text { Received: January 14, } 2020 \\
\text { Accepted: June 5, } 2020 \\
\text { Published online: November 25, } 2020\end{array}$ & $\begin{array}{l}\text { Abstract } \\
\text { The present study evaluated the effect of methanol extract of Cassia } \\
\text { occidentalis L. root on selected liver enzymes, kidney function parameters, } \\
\text { liver and kidney. Six groups of rats were used. Diabetes was induced by } \\
\text { alloxan ( } 150 \mathrm{mg} / \mathrm{kgbwt} \text { ) administered intraperitoneally. Diabetic rats were } \\
\text { orally administered } C \text {. occidentalis root extract ( } 300,400 \text { and } 600 \mathrm{mg} / \mathrm{kgbwt} \text {, } \\
\text { respectively) and metformin (standard drug). Alloxan induction led to a } \\
\text { significant (p<0.05) increase in serum creatinine, urea, bilirubin, alkaline } \\
\text { phosphatase, aspartate aminotransferase and alanine aminotransferase, while } \\
\text { a significant decrease was observed for serum electrolytes }\left(\mathrm{Na}^{+}, \mathrm{K}^{+} \text {and } \mathrm{Cl}^{-} \text {). }\right. \\
\text { Treatment with the varying doses of } C \text {. occidentalis extract and metformin } \\
\text { significantly reduced and increased (p<0.05) the serum levels of these various } \\
\text { parameters respectively. Histopathological studies on the liver from diabetic } \\
\text { rats showed hepatocellular injury which resulted in the loss of the normal } \\
\text { architecture of the liver tissues, subtle focal hepatocyte necrosis and vesicular } \\
\text { steatosis while that of the kidney showed focal interstitial infiltration by } \\
\text { lymphocytes and macrophages. Treatment significantly reversed the damages } \\
\text { observed in both tissues. The present study showed that } C \text {. occidentalis was } \\
\text { able to alleviate the liver and renal injury that was observed in alloxan- } \\
\text { induced diabetic rats. } \\
\text { Keywords: Alloxan, Cassia occidentalis, diabetes, kidney, liver, rats }\end{array}$ \\
\hline
\end{tabular}

\section{INTRODUCTION}

Plants as natural products are indispensable components required in therapeutic medicine due to their ability to produce secondary metabolites such as flavonoids, steroids, terpenes, anthraquinones, etc. Consequently, they can be used as a welcomed font for curing numerous health challenges and improving overall well-being (Sharanaiah et al., 2013). Current advances in processes involving drug discovery and development are paying attention to natural sources, particularly those of plant origin due to several established correlations between the customary therapeutic uses of a number of these natural products to biological activity. As a result, over the years the application of plant materials to successfully avert and treat infectious diseases has continued to interest scientists' all over the universe (Egharevba et al., 2010).

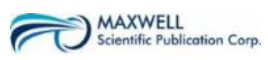

(C) The Author(s) 2020. This article is licensed under a Creative Commons Attribution 4.0 International License, which permits use, sharing, adaptation, distribution and reproduction in any medium or format, as long as you give appropriate credit to the original author(s) and the source, provide a link to the Creative Commons license, and indicate if changes were made. The images or other third-party material in this article are included in the article's Creative Commons license, unless indicated otherwise in a credit line to the material. If material is not included in the article's Creative Commons license and your intended use is not permitted by statutory regulation or exceeds the permitted use, you will need to obtain permission directly from the copyright holder. To view a copy of this license, visit http://creativecommons.org/ licenses/by/4.0/. 
Diabetes mellitus is a metabolic disorder that ensues from a deficiency in insulin release, insulin function, or the duo (Beverley and Eschwege, 2003), resulting in a constant rise in blood sugar levels with carbohydrate, fat and protein metabolism been affected. As diabetes advances vascular damage develops, if uncontrolled could affect vital body organs resulting to severe complications such as cardiovascular diseases, nephropathy, neuropathy, retinopathy and foot ulceration (Looker et al., 2003; Hove et al., 2004; Seki et al., 2004; Svensson et al., 2004; Saely et al., 2004). Thus, it covers a broad array of multiple diseases. Cassia occidentalis, known as coffee senna or stinking weed in English is a shrub typically native to America and is widespread in temperate regions of the world. Coffee senna is a hedge plant used for landscape purposes (Hussein, 2003). It belongs to the family Caesalpiniaceae. The parts of the plant used for medicinal purposes are the roots, leaves and seeds. It is an upright herb, commonly seen by waysides, trenches and refuse dumping sites. C. occidentalis has been widely used as traditional medicine. Entire parts of the plant have medicinal values (Mohammed et al., 2012). The study was carried out to investigate the effect of $C$. occidentalis on selected liver enzymes, kidney function parameters, liver and kidney of alloxan-induced diabetic rats.

\section{MATERIALS AND METHODS}

Study site: The Department of Biochemistry, School of Life Sciences, Federal University of Technology, Minna, Nigeria.

Collection of plant material: Fresh root samples of C. occidentalis were collected from New Bussa town (Borgu) in Niger State, Nigeria in April 2014. The plant was identified and authenticated at the National Institute for Pharmaceutical Research and Development, Idu Abuja, Nigeria (Department of Medicinal Plant Research and Traditional Medicine Herbarium and Ethnobotany Unit) and, voucher number NIPRD/H/6629 was deposited.

Preparation of plant sample: The root of C. occidentalis was rinsed with clean water, cut into tiny pieces and air-dried at room temperature. When dried, the root was powdered using a blender (Excella Marlex Electroline LBD 4872) and passed through a sieve to obtain a fine powder which was then stored in an airtight container for further use.
Preparation of extract: The powdered root (50 g) was weighed using a weighing balance and extracted in 400 $\mathrm{mL}$ of absolute methanol and heated for $3 \mathrm{~h}$ at $65^{\circ} \mathrm{C}$ in a reflux extractor, after which it was filtered using a muslin cloth. The filtrate was concentrated in a rotary evaporator and then a Water bath to a semi-solid mass. The extract obtained thereafter was kept in an airtight sample bottle and stored in the refrigerator.

Animal model: A total of 24 Wistar albino rats of either sex weighing between 150-250 g were obtained from National Veterinary Research Institute Vom in Jos, Nigeria. The rats were kept in clean plastic cages and housed under suitable conditions in the Department of Biochemistry Laboratory, Federal University of Technology Minna, Niger State. They were provided with food and water ad libitum and allowed to acclimatize to the laboratory environment for two weeks before proceeding with the experiment. The cages in which the rats are kept were cleaned regularly throughout the experiment. The study was conducted according to the Principles of Laboratory Animal Care, (WHO Expert Committee, 1985).

Experimental induction of diabetes: Healthy Albino rats of either sex were fasted overnight and hyperglycemia was induced by a single intraperitoneal injection of $150 \mathrm{mg} / \mathrm{kgbwt}$ alloxan monohydrate freshly dissolved in normal saline immediately before been used to overnight feed-fasted albino rats and feeding was resumed an hour after alloxan injection. Seventy-two h after alloxan induction the blood glucose of each animal was checked using a glucometer (AccuCheck Active). Each animal with a blood glucose level of $250 \mathrm{mg} / \mathrm{dL}$ and above were considered as diabetic and used for the study (Verma et al., 2010). To overcome the hypoglycemia which might occur during the first $24 \mathrm{~h}$ following the alloxan administration, diabetic rats were given $5 \%$ glucose solution orally.

Animal grouping and treatment: After the confirmation of diabetes in the induced animals, 24 rats were randomly selected and divided into 6 groups each containing 4 animals:

- Group 1 (NCL): Normal control (Saline) (Not induced)

- Group 2 (DNT): Diabetic control (Alloxan-150 $\mathrm{mg} / \mathrm{kgbwt}$ ) (induced not treated)

- Group 3 (STD): Standard Drug (metformin-5 $\mathrm{mg} / \mathrm{kg}$ ) 
- Group 4 (CO1): Dose-1 $300 \mathrm{mg} / \mathrm{kgbwt}$ of extract (induced and treated)

- Group 5 (CO2): Dose-2 $400 \mathrm{mg} / \mathrm{kgbwt}$ of extract (induced and treated)

- Group 6 (CO3): Dose-3 $600 \mathrm{mg} / \mathrm{kgbwt}$ of extract (induced and treated)

Animals were treated once daily for a period of 14 days. A moderate to high dose was chosen randomly for the study according to the LD50 of the whole plant and that of the root as reported in the literature (Verma et al., 2010; Tona et al., 2001).

Blood collection and serum preparation: Twenty-four hour after the final treatment, the animals were anesthetized using diethyl ether and blood samples were collected through jugular puncture. The blood samples were allowed to stand at room temperature for $30 \mathrm{~min}$ and then centrifuged at $1500 \mathrm{rpm}$ for $15 \mathrm{~min}$.

Estimation of selected liver enzymes and kidney function parameters: Alkaline phosphatase, total and direct bilirubin, urea and creatinine were analyzed using Randox Diagnostic kits as described by Rec. GSCC (DGKC) (1972) and Jendrassik and Grof (1938), sodium and chloride were estimated using Teco kits as described by Trinder (1951) and Skeggs and Hochestrasse (1964), while potassium, alanine aminotransferase and aspartate aminotransferase were estimated using Reflotron Plus Chemistry Analyzer (Model No. RS232 CENTRONICS).

Statistical analysis: Data obtained from the study were subjected to a one-way Analysis of Variance (ANOVA) followed by post-hoc Duncan Test for comparison using SPSS version 16.0. Significance was accepted at $p<0.05$ and results were expressed as mean \pm standard error of the mean.

\section{RESULTS}

Effect of methanol root extract of Cassia occidentalis on serum liver enzymes: Figure 1, shows the effect of both the extract and standard drug on Alanine Aminotransferase (ALT), Aspartate Aminotransferase (AST) and Alkaline Phosphatase (ALP). The levels of the liver enzymes in the diabetic control group are elevated in comparison to the normal control $(\mathrm{p}<0.05)$. Oral administration of the extract was able to significantly reduce the elevated serum enzyme levels.
Effect of methanol extract of Cassia occidentalis on serum electrolytes of rats: Figure 2, shows the effect of the extract on serum electrolytes particularly sodium $\left(\mathrm{Na}^{+}\right)$and chloride $\left(\mathrm{Cl}^{-}\right)$, there was a significant decrease

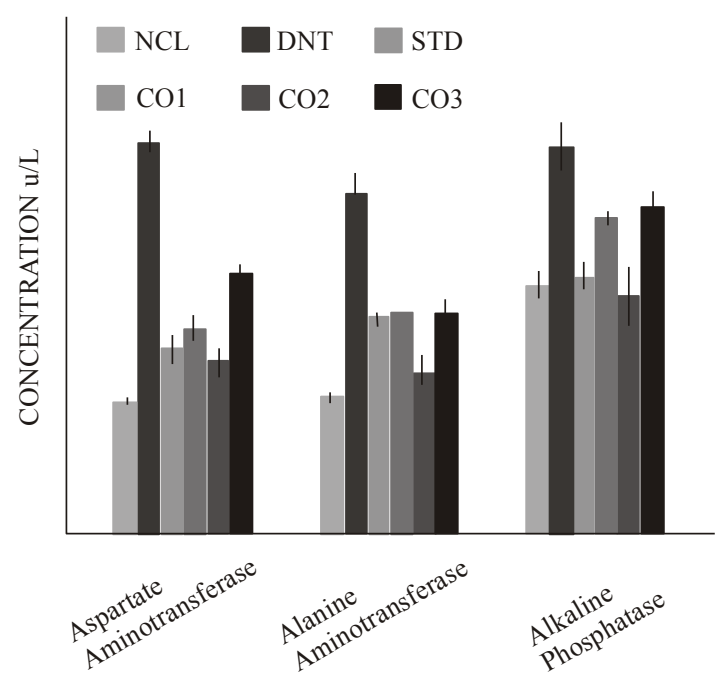

Fig. 1: Effect of methanol extract of Cassia occidentalis on serum liver enzymes of rats

NCL: Normal control; DNT: Induced not treated; STD: Induced and treated (metformin- $5 \mathrm{mg} / \mathrm{kgbwt}$ ); $\mathrm{CO} 1$ : Induced and treated (root extract-300 mg/kgbwt); $\mathrm{CO} 2$ : Induced and treated (root extract- $400 \mathrm{mg} / \mathrm{kgbwt}$ ); $\mathrm{CO} 3$ : Induced and treated (root extract-600 mg/kgbwt)

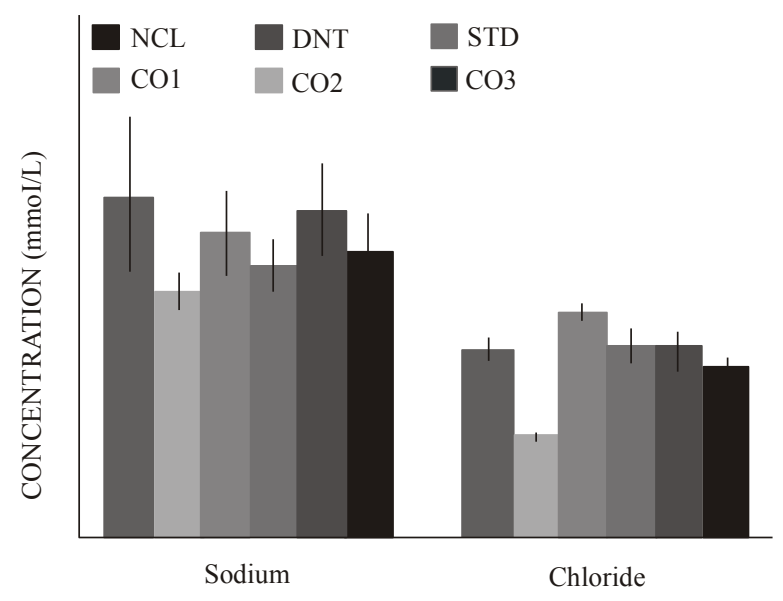

Fig. 2: Serum sodium and chloride levels in diabetic treated and untreated rats

NCL: Normal control; DNT: Induced not treated; STD: Induced and treated (metformin-5 mg/kgbwt); $\mathrm{CO} 1$ : Induced and treated (root extract- $300 \mathrm{mg} / \mathrm{kgbwt}$ ); $\mathrm{CO} 2$ : Induced and treated (root extract- $400 \mathrm{mg} / \mathrm{kgbwt}$ ); CO3: Induced and treated (root extract- $600 \mathrm{mg} / \mathrm{kgbwt}$ ) 


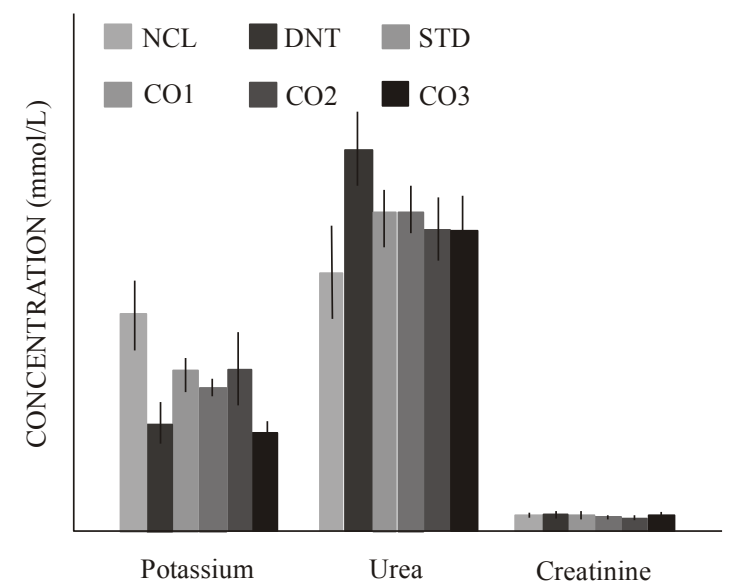

Fig. 3: Serum levels of potassium, urea and creatinine in treated and untreated diabetic rats

NCL: Normal control; DNT: Induced not treated; STD: Induced and treated (metformin-5 mg/kgbwt); CO1: Induced and treated (root extract-300 $\mathrm{mg} / \mathrm{kgbwt}$ ); $\mathrm{CO} 2$ : Induced and treated (root extract-400 mg/kgbwt); CO3: Induced and treated (root extract- $600 \mathrm{mg} / \mathrm{kgbwt}$ )

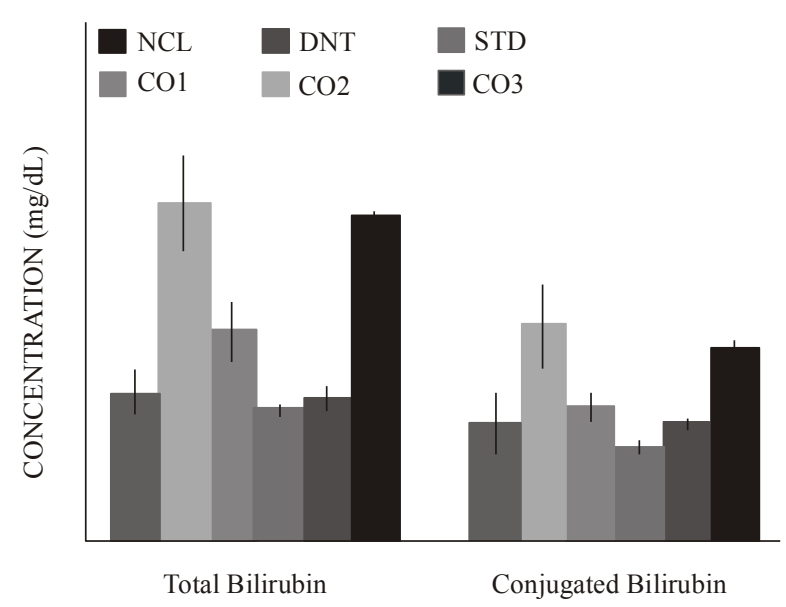

Fig. 4: Serum bilirubin (total and conjugated) levels of diabetic treated and untreated rats

NCL: Normal control; DNT: Induced not treated; STD: Induced and treated (metformin-5 mg/kgbwt); CO1: Induced and treated (root extract-300 mg/kgbwt); $\mathrm{CO} 2$ : Induced and treated (root extract-400 mg/kgbwt); CO3: Induced and treated (root extract- $600 \mathrm{mg} / \mathrm{kgbwt}$ )

in the plasma levels of sodium and chloride in the diabetic group when compared to normal control. After treatment with various doses of the extract and the standard drug the level increased significantly $(p<0.05)$. With the groups kept on the standard drug and 400 $\mathrm{mg} / \mathrm{kgbwt}$ being comparable to the normal control.
Figure 3 shows the effect of the extract on potassium, urea and creatinine. A significant increase was observed in the level of urea in the serum, an increase in creatinine level which was non-significant $(\mathrm{p}>0.05)$ and a significant decrease in potassium level in diabetic group when compared to the normal control group. Oral administration of various treatment to the corresponding groups was able to significantly $(p<0.05)$ correct the changes observed.

Effects of methanol extracts of Cassia occidentalis on bilirubin: The serum concentrations of bilirubin (total and conjugated) for each group are represented in Fig. 4. The diabetic group (DNT) and the group treated with the highest dosage (CO3) had significantly high bilirubin levels when compared to the Normal Control Group (NCL).

Histopathological study on the liver and kidney of rats: Histopathological sections of the liver of alloxaninduced diabetic rats showed hepatocellular injury which articulated in loss of the normal architecture of the liver, subtle focal hepatocyte necrosis, ballooning degeneration with focal macrovesicular steatosis was observed, which is consistent with a diabetic state. In contrast, the liver section of rats treated with $C$. occidentalis extract at the specified doses showed improved hepatocellular architecture with a sign of recovery. Specifically, the Section of the liver showed hepatic tissue with regenerative changes characterized by architectural disarray and thickened plates of hepatocytes (Plates 1 to 6).

The histological study carried out on the kidneys of untreated diabetic rats showed focal tubulointerstitial However, the photomicrograph of the rats treated with the highest dose $(600 \mathrm{mg} / \mathrm{kgbwt})$ also showed infiltration by the lymphocytes, macrophages and few neutrophils which are consistent with acute kidney injury. The treated diabetic rats showed healing features, which resembled that of a normal kidney infiltration by the lymphocytes and macrophages (Plate 7 to 12 ).

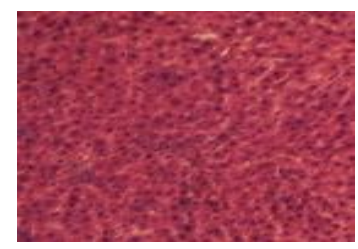

Plate 1: Photomicrograph of the liver section of a rat that was administered normal saline

Section of the liver shows the normal histology of the liver 


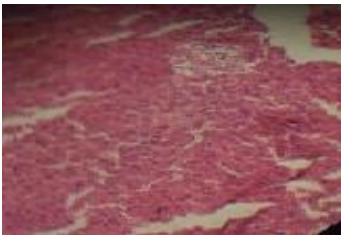

Plate 2: Photomicrograph of the liver section of rat induced with diabetes but not treated

Section of the liver shows ballooning degeneration with focal macrovesicular steatosis

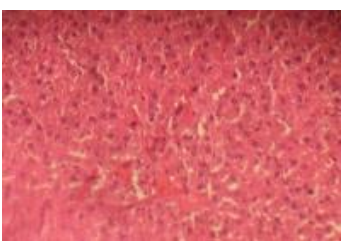

Plate 3: Photomicrograph of the liver of rat induced and treated with standard drug (metformin)

Section of the liver show no pathological changes

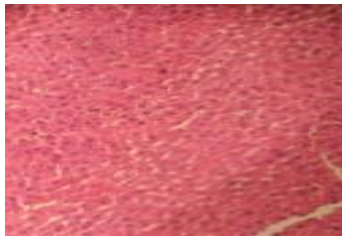

Plate 4: Photomicrograph of the liver of rat induced and treated with $300 \mathrm{mg} / \mathrm{kgbwt}$

No pathological changes observed

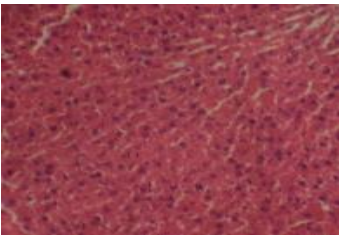

Plate 5: Photomicrograph of the liver of rat induced and treated with $400 \mathrm{mg} / \mathrm{kgbwt}$ No pathological changes seen

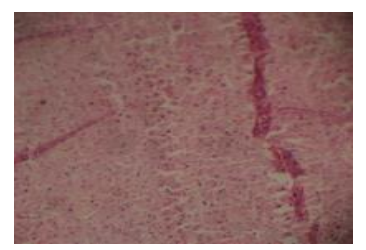

Plate 6: Photomicrograph of the liver of rat induced and treated with $600 \mathrm{mg} / \mathrm{kgbwt}$

Section of the liver shows hepatic tissue with regenerative changes characterized by architectural disarray coupled with thickened plates of hepatocytes

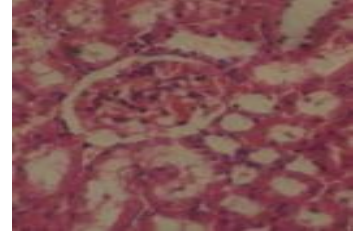

Plate 7: Photomicrograph of the kidney section of rat that was administered normal saline

Section of the kidney shows the normal histology of the kidney

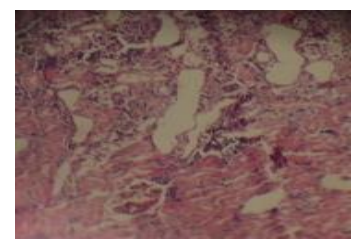

Plate 8: Photomicrograph of the kidney section of rat induced with diabetes but not treated

Section of the kidney shows focal tubulointerstitial infiltration by the lymphocytes

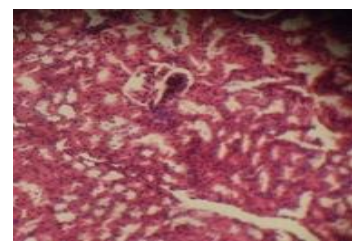

Plate 9: Photomicrograph of the kidney of rat induced and treated with standard drug (metformin) No pathological changes were seen

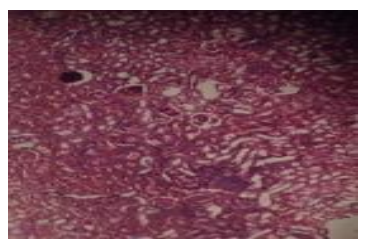

Plate 10: Photomicrograph of the kidney of rat induced and treated with $300 \mathrm{mg} / \mathrm{kgbwt}$

No pathological changes but regenerative changes were observed

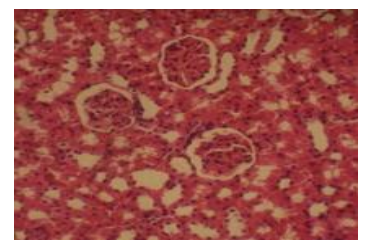

Plate 11: Photomicrograph of the kidney of rat induced and treated with $400 \mathrm{mg} / \mathrm{kgbwt}$

No pathological changes where observed 


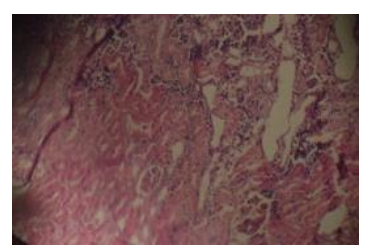

Plate 12: Photomicrograph of the kidney of rat induced and treated with $600 \mathrm{mg} / \mathrm{kgbwt}$

Section of the kidney shows renal tissue with focal tubulointerstitial infiltration by the lymphocytes

\section{DISCUSSION}

Biochemical parameters are affected by herbal extracts and various physiological abnormalities such as in a diabetic condition. It had been postulated that elevations in the levels of diagnostic enzymes in the serum could be due to a rise in the rate at which these enzymes are synthesized as a result of their induction by certain drugs among other factors.

The increase in the activities of serum Aspartate Aminotransferase (AST), Alanine Aminotransferase (ALT) and Alkaline Phosphatase (ALP) (Fig. 1) is indicative of the fact that some kind of inflammation or damage are causing the enzymes to seep out of the liver cells and fatty liver which has diabetes as its risk factor is the most common cause of this. Supporting this finding is the histopathological studies carried out on the liver of the diabetic untreated group which showed subtle hepatocyte necrosis and ballooning degeneration with focal macro vesicular steatosis. Therefore, the elevation in the activities of AST, ALT and ALP in serum may be largely owing to the seepage of these enzymes from the liver cytosol into the blood (Navarro et al., 1993), which indicates the hepatotoxicity of alloxan monohydrate. On the other hand, the treatment of the diabetic rats with the various doses of the root extract and the standard drug caused a reduction in the activity of these enzymes in the serum (Fig. 1) compared to the mean values of the diabetic group. These results are in agreement with those obtained by Ohaeri (2001) in rats and Saligram et al. (2012) in human subjects. Enemor et al. (2014) observed an insignificant decrease in ALP but a significant decrease in ALT and AST following the administration of various doses of Sarcocephelu latifolus root extract. The reported significant decrease was inferred to be attributed to the consequence of enzyme inhibitory effects of the plant extract while a decrease could be attributed to the presence of cellular damage (Balamurugan et al., 2009). However, Nuhu and Aliyu (2008) reported a contrary result which observed a significant increase in liver enzymes of rats administered with aqueous extract of the leaves of $C$. occidentalis at various doses of 300,600 and $900 \mathrm{mg} / \mathrm{kgbwt}$, respectively. This observation by Nuhu and Aliyu (2008) was attributed to liver injury which may be caused by the extract, and concluded that the aqueous leaf extract of C. occidentalis is slightly toxic to the liver. Though reduction of increased serum levels of liver enzymes at the dose of $600 \mathrm{mg} / \mathrm{kgbwt}$ was less compared to other treatment groups and the histopathological studies carried on the liver of the animals in this group showed hepatic tissue with regenerative changes characterized by architectural disarray and thickened plates of hepatocytes. There was associated interface steatohepatitis and bile ductular reaction while the other dose levels used in this study showed improved hepatocellular architecture with a sign of recovery. This observation could be attributed to the fact that high concentration of certain drugs affect their bioavailability as a result perhaps the amount that was absorbed was not enough to initiate the repair which could probably restore the liver injury that might have resulted from alloxan induction because there were regenerative changes which is a sign of recovery and there was also interface steatohepatitis which is an indication that the liver injury as a result of fat accumulation was not resolved. This finding could not be compared with reported literature however it was reported that the aqueous root extract of C. occidentalis at $200 \mathrm{mg} / \mathrm{kgbwt}$ was found to be hepatoprotective (Usha and Bopaiah, 2012).

Electrolyte and fluid imbalances are common in diabetes and have been attributed to their increased loss in urine, reduced intake and absorption (Macallan, 1999). These imbalances resulting from kidney failure, dehydration and fever has been suggested as one of the contributing factors toward complications observed in diabetes and other endocrine disorders (Tanko et al., 2013). In this study the serum concentrations of sodium, chloride and potassium were significantly low in the diabetic control when compared to the normal control (Fig. 2 and 3). This is consistent with reports of Prohp and Onoagbe (2014), Eteng et al. (2008) and Ikpi et al. (2009). The fact that kidney function is compromised in untreated diabetes is well acknowledged (Ikpi et al., 2009). Glycosuria (excretion of glucose in urine) results in dehydration via glucose osmotic diuresis which is in turn accompanied by a severe loss of electrolytes (Eteng et al., 2008). Oral administration of the root extract and metformin was able to significantly improve the electrolyte imbalance that was observed and this might be ascribed to the ability of the root extract to resolve the osmotic diuresis and improve kidney dysfunction. 
An increase in serum creatinine and urea levels may be a sign of renal dysfunction in the animals affected. According to Wasan et al. (2001) elevation in the serum creatinine and urea concentrations indirectly suggests kidney damage specifically the renal filtration mechanism. The results in Fig. 3 show a significant increase in serum creatinine and urea levels in nontreated group when compared to the normal group, while after treatment with $C$. occidentalis root extract at the doses of 300, 400 and $600 \mathrm{mg} / \mathrm{kgbwt}$, respectively together with metformin (5 mg/kgbwt) were able to alleviate the elevation observed this is in agreement with previous studies (Daisy and Kani, 2013; Ahmed et al., 2005; Mansour et al., 2002) with the basis of the reduction not mentioned in the reports except for Daisy and Kani (2013) who attributed it to the antidiabetic action of the plant (Cassia auriculata) used in the study which resulted in alleviation of altered metabolism status in animals. Thus, in the present study the basis for the reductive effect might be ascribed to the ability of the extract to reverse the adverse effect of alloxan on kidney function.

Bilirubin has been shown to increase in the blood as a consequence of regurgitation of bile owing to a blockage within the liver as a result of the inflammation caused by diabetes (Schaefer et al., 2002) and this subsequently has been shown to increase ALP activity (Stocker et al., 1987). The finding in Fig. 4 showed that the diabetic untreated group had a markedly $(\mathrm{p}<0.05)$ elevated level of plasma bilirubin. However, treatment gave rise to a significant $(\mathrm{p}<0.05)$ decrease in plasma bilirubin. Rana et al. (1996) reported that the increment in plasma bilirubin may occur as a result of the abatement of liver uptake, conjugation, or increment of bilirubin formation as a result of hemolysis, which has been shown to result in reduced total erythrocyte counts (El-Demerdash et al., 2004). The increase in serum bilirubin from this study could be as a result of liver injury.

\section{CONCLUSION}

It can be concluded from this present study that the extract at moderate doses is capable of alleviating the renal and hepatic damages which results from alloxan induction and this could be attributed to the phytochemicals present in the extract. Thus, further researches are recommended to isolate and purify these phytochemicals.

\section{ACKNOWLEDGMENT}

The authors are grateful to the management and Staff of the Biochemistry Department, Federal University of Technology, Minna, Nigeria.

\section{REFERENCES}

Ahmed, S.M., B.M. Vrushabendra Swamy, P. Gopkumar, R. Dhanapal and V.M. Chandrashekara, 2005. Anti-diabetic activity of Terminalia catappa Linn. leaf extracts in alloxan-induced diabetic rats. Iran. J. Pharmacol. Therapeut., 4: 36-39.

Balamurugan, K., G. Vanithakumari and N. Indra, 2009. Effect of rifampicin on certain biochemical parameter in the liver of albino rats. Int. J. Toxicol., 6(1): 1.

Beverley, B. and E. Eschwège, 2003. The Diagnosis and Classification of Diabetes and Impaired Glucose Tolerance. In: John, C.P. and W. Gareth (Eds.), Textbook of Diabetes 1. Blackwell Science, Malden, Mass, Oxford, U.K., pp: 2.1-2.1.

Daisy, P. and F.G.J. Kani, 2013. Hypolipidemic and hepatoprotective effects of Cassia auriculata Linn bark extracts on streptozotocin induced diabetics in male wister albino rats. Asian J. Pharmaceut. Clin. Res., 6(2): 43-48.

Egharevba, H.O., A.C. Odigwe, M.S. Abdullahi, S.K. Okwute and J.I. Okogun, 2010. Phytochemical analysis and broad spectrum antimicrobial activity of Cassia occidentalis L. (whole plant). New York Sci. J., 3(10): 74-81.

El-Demerdash, F.M., M.I. Yousef and N.I. Abou ElNaga, 2004. Biochemical study on the hypoglycemic effects of onion and garlic in alloxaninduced diabetic rats. Food Chem. Toxicol., 43: 57-63.

Enemor, V.H.A., A.N.C. Okaka and S.A. Enemor, 2014. In vivio analyses of acute and sub-acute effects of orally administered ethanol extract of root of Sarcocepalus latifolius (African peach) on kidney function markers of Wistar albino rats. J. Biol. Chem. Res., 31(1): 299-308.

Eteng, M.U., H.A. Ibekwe, A.D. Essien and H.P. Onyeama, 2008. Effects of Cataranthus roseus on electrolyte derangement induced by chlorpropamide $(\text { Diabinese })^{\mathrm{R}}$ on Normoglycemic Albino Wistar rat. Bio-Res., 6(2): 364-366.

Hove, M.N., J.K. Kristensen, T. Lauritzen and T. Bek, 2004. The prevalence of retinopathy in an unselected population of type 2 diabetes patients from Arhus County, Denmark. Acta Ophthalmol. Scand., 82: 443-448.

Hussein, M.M.M., 2003. Growth of Senna occidentalis (L.) link in sandy soil as affected by fertilization and some amendments. Cairo Univ., Bull. Fac. Agric., 54: $189-216$. 
Ikpi, D.E., A.O. Obembe and C.O. Nku, 2009. Aqueous leaf extract of Rothmannia longiflora improves basal metabolic rate and electrolyte parameters in alloxan-induced diabetic rats. Niger. J. Physiol. Sci., 24(1): 67-71.

Jendrassik, L. and P. Grof, 1938. Simplified photometric methods for the determination of the blood bilirubin. Biochem. Zeitschrift, 297: 81.

Looker, H.C., A. Fagot-Campagna, E.W. Gunter, C.M. Pfeiffer, K.M. Venkat Narayan, W.C. Knowler and R.L. Hanson, 2003. Homocysteine as a risk factor for nephropathy and retinopathy in type 2 diabetes. Diabetologia, 46: 766-772.

Macallan, D.C., 1999. Wasting in HIV infection and AIDS. J. Nutr., 129: 238S-242S.

Mansour, H.A., A.S.A. Newairy, M.I. Yousef and S.A. Sheweita, 2002. Biochemical study on the effects of some Egyptian herbs in alloxan-induced diabetic rats. Toxicology, 170: 221-228.

Mohammed, M., M.A. Aboki, H.M. Saidu, O. Victor, A. Tawakalitu and S.A. Maikano, 2012. Phytochemical and some antimicrobial activity of Cassia occidentalis L. (caesalpiniaceae). Int. J. Sci. Technol., 2(4): 200-209.

Navarro, M.C., M.P. Montilla, A. Martin, J. Jimenez and M.P. Utrilla, 1993. Free radical scavenger and antihepatotoxic activity of Rosmarinus tomentosus. Planta Med., 59: 312-314.

Nuhu, A.A. and R. Aliyu, 2008. Effects of Cassia occidentalis aqueous leaf extract on biochemical markers of tissue damage in rats. Trop. J. Pharmaceut. Res., 7(4): 1137-1142.

Ohaeri, O.C., 2001. Effect of garlic oil on the levels of various enzymes in the serum and tissue of streptozotocin diabetic rats. Bioscience Rep., 21: 19-24.

Prohp, T.P. and I.O. Onoagbe, 2014. Plasma electrolyte concentrations in normal and streptozotocininduced diabetic rats treated with extracts of Triplochiton scleroxylon K. Schum. Am. J. Res. Commun., 2(5): 154-174.

Rana, S.V., R. Singh and S. Verma, 1996. Protective effects of few antioxidants on liver function in rats treated with cadmium and mercury. Indian J. Exp. Biol., 34(2): 177-179.

Rec. GSCC (DGKC), 1972. Optimized standard colorimetric methods. J. Clin. Chem. Clin. Bio., 10: 182.

Saely, C.H., S. Aczel, T. Marte, P. Langer and H. Drexel, 2004. Cardiovascular complications in type 2 diabetes mellitus depend on the coronary angiographic state rather than on the diabetic state. Diabetologia, 47: 145-146.
Saligram, S., E.J. Williams and M.G. Masding, 2012. Raised liver enzymes in newly diagnosed type 2 diabetes are associated with weight and lipids, but not glycaemic control. Indian J. Endocrinol. Metab., 16(6): 1012-1014.

Schaefer, E.J., J.R. McNamara, P.K. Shah, K. Nakajima, L.A. Cupples et al., 2002. Elevated remnant-like particle cholesterol and triglyceride levels in diabetic men and women in the Framingham offspring study. Diabetes Care, 25: 989-994.

Seki, M., T. Tanaka, H. Nawa, T. Usui, T. Fukuchi, K. Ikeda, H. Abe and N. Takei, 2004. Involvement of brain-derived neurotrophic factor in early retinal neuropathy of streptozotocin-induced diabetes in rats: therapeutic potential of brain-derived neurotrophic factor for dopaminergic amacrine cells. Diabetes, 53: 2412-2419.

Sharanaiah, U., M. Shirin and A. Mohammed, 2013. Antioxidant and antidiabetic activities of medicinal plants: A short review. Int. J. Res. Phytochem. Pharmacol., 3(1): 40-53.

Skeggs, L.T. and H. Hochstrasser, 1964. Multiple automatic sequential analysis. Clin. Chem., 10: 918-936.

Stocker, R., Y. Yamamoto, A.F. McDonagh, A.N. Glazer and B.N. Ames, 1987. Bilirubin is an antioxidant of possible physiological importance. Science, 235: 1043-1046.

Svensson, M., J.W. Eriksson and G. Dahlquist, 2004. Early glycemic control, age at onset, and development of microvascular complications in childhood-onset type 1 diabetes: A populationbased study in northern Sweden. Diabetes Care, 27: 955-962.

Tanko, Y., N.H. Sada, K.A. Mohammed, M. Yerima and J. Mohammed, 2013. Ethanolic extract of Caralluma diazielii on serum electrolytes levels on fructose-induced diabetes in Wistar. Ann. Biol. Res., 4(2):157-161.

Tona, L., K. Mesia, N.P. Ngimbi, B. Chrimwami, O. Ahoka, K. Cimanga et al., 2001. In-vivo antimalarial activity of Cassia occidentalis, Morinda morindoides and Phyllanthus niruri. Ann. Trop. Med. Parasit., 95: 47-57.

Trinder, P., 1951. A rapid method for the determination of sodium in serum. Analyst, 76: 596.

Usha, V. and A.K. Bopaiah, 2012. Phytochemical investigation of the ethanol, methanol and ethyl acetate leaf extracts of six cassia species. Int. J. Pharmacol. Bio Sci., 3(2): 260-270. 
Verma, L., K. Anirudh, K. Basant, K.P. Umesh and S.P. Rajesh, 2010. Antidiabetic activity of Cassia occidentalis (Linn) in normal and alloxan-induced diabetic rats. Indian J. Pharmacol., 42(4): 224-228.

Wasan, K.M., S. Najafi, J. Wong, M. Kwong and P.H. Pritchard, 2001. Assessing plasma lipid levels, body weight, and hepatic and renal toxicity following chronic oral administration of a water soluble phytostanol compound, FM-VP4, to gerbils. J. Pharm. Pharm. Sci., 4(3): 228-234.

WHO Expert Committee, 1985. Diabetes mellitus. WHO Technical Report Series 727, Geneva. 